\title{
Cap-prevented recombination between terminal telomeric repeat arrays (telomere CPR) maintains telomeres in Kluyveromyces lactis lacking telomerase
}

\author{
Michael J. McEachern and Elizabeth H. Blackburn ${ }^{1}$ \\ Department of Microbiology and Immunology, University of California, San Francisco, \\ San Francisco, California 94143-0414 USA
}

\begin{abstract}
Deletion of the telomerase RNA gene (TER1) in the yeast Kluyveromyces lactis results in gradual loss of telomeric repeats and progressively declining cell growth capability (growth senescence). We show that this initial growth senescence is characterized by abnormally large, defectively dividing cells and is delayed when cells initially contain elongated telomeres. However, cells that survive the initial catastrophic senescence emerge relatively frequently, and their subsequent growth without telomerase is surprisingly efficient. Survivors have lengthened telomeres, often much longer than wild type, but that are still subject to gradual shortening. Production of these postsenescence survivors is strongly dependent on the RAD52 gene. We propose that shortened, terminal telomeric repeat tracts become uncapped, promoting recombinational repair between them to regenerate lengthened telomeres in survivors. This process, which we term telomere cap-prevented recombination (CPR) may be a general alternative telomere maintenance pathway in eukaryotes.
\end{abstract}

[Key Words: Kluyveromyces lactis; cap-prevented recombination; telomere maintenance; telomerase RNA]

Received April 9, 1996; revised version accepted June 12, 1996.

Telomeres are the DNA-protein complexes at the ends of eukaryotic chromosomes. In a wide range of eukaryotes, the telomeric DNA consists of tandem copies of a short $(5-26 \mathrm{bp})$ repeat sequence present in arrays ranging from tens to tens of thousands of base pairs in length, depending on the species (Biessmann and Mason 1992; McEachern and Hicks 1993; Blackburn 1994; Cohn and Blackburn 1995; Henderson 1995). Because one strand of a DNA end cannot be completely replicated by the normal cellular DNA polymerases, an essential function of telomeres is to provide a means of fully replicating chromosome ends. Eukaryotic cells normally compensate for incomplete replication with the ribonucleoprotein reverse transcriptase telomerase. Telomerase activity, which has been characterized in diverse eukaryotes (for review, see Greider 1995) adds telomeric sequences de novo onto chromosome ends by using part of its RNA subunit as the template for the synthesis of a telomeric repeat unit. Genes encoding the RNA component of telomerase have been cloned from many ciliates, the yeasts Saccharomyces cerevisiae and Kluyveromyces lactis, and human and mouse /Greider and Blackburn 1989; Shippen-Lentz and Blackburn 1990; Romero and Blackburn 1991; Lingner et al. 1994; Singer and Gottschling 1994; Blasco et al. 1995; Feng et al. 1995;

${ }^{1}$ Corresponding author.
McEachern and Blackburn 1995). Base changes made within the template sequence of the telomerase RNA gene cause synthesis of telomeric repeats with the corresponding sequence changes and can have severe consequences for cells, including nuclear and cellular division defects, cell death, and runaway telomere lengthening (Yu et al. 1990; Yu and Blackburn 1991; McEachern and Blackburn 1995). Loss of telomerase RNA function, by point mutation in Tetrahymena or gene deletion in $S$. cerevisiae or $K$. lactis, causes progressive loss of telomeric DNA and cellular growth senescence / Yu et al. 1990; Singer and Gottschling 1994; McEachern and Blackburn 1995).

In addition to their role in chromosome replication, telomeres are also thought to form a cap that prevents chromosome ends from being degraded or fused together. For example, in $S$. cerevisiae cells incapable of utilizing homologous recombination to repair the break, removal of a telomere or introduction of a single or multiple double-strand breaks (DSBs) induces a $R A D$ 9-dependent cell cycle arrest (Weinert and Hartwell 1988; Schiestl et al. 1989; Bennett et al. 1993; Sandell and Zakian 1993). Upon resumption of cell growth, a chromosome missing a telomere is lost at an extremely high rate (Sandell and Zakian 1993). These results demonstrate the essential roles of yeast telomeres in chromosome stability and in preventing chromosome ends from being mistaken for DSBs. 
S. cerevisiae cells with mutations in the EST1 gene gradually lose telomeric sequences and undergo growth senescence, indicating that telomeres are essential for cell growth (Lundblad and Szostak 1989). Although EST1 is not a catalytic component of telomerase (Cohn and Blackburn 1995), the same phenotypes are produced by deleting the $S$. cerevisiae telomerase RNA gene TLC1 (Singer and Gottschling 1994). Whereas most est1 cells die within 50-100 generations, some survive beyond this point and have dramatic extents of tandem amplifications of subtelomeric repeat sequences (Lundblad and Blackburn 1993). These amplifications are dependent on RAD52 gene function and hence, by inference, on homologous recombination (Lundblad and Blackburn 1993). As $S$. cerevisiae contains arrays of the telomeric $\mathrm{TG}_{1-3}$ repeat sequences not only at telomeric termini but also at subtelomeric locations on many chromosome ends, it was postulated that a pathway involving gene conversion allows est 1 cells to survive by recombining internally located telomere-like arrays onto chromosomal termini (Lundblad and Blackburn 1993). As most other eukaryotes studied lack similar subtelomeric reservoirs of telomeric repeats, it has been unclear whether recombination can maintain chromosome ends in species other than $S$. cerevisiae.

The yeast $K$. lactis is one of several yeast species with unusually long telomeric repeats (McEachern and Hicks 1993; McEachern and Blackburn 1994). Each of the $12 \mathrm{~K}$. lactis telomeres is composed of a terminal array of $\sim 10$ 20 tandem copies of a perfect 25-bp repeat (McEachern and Blackburn 1994). The only other telomere homology in the genome of $K$. lactis is the telomerase RNA gene TER1, which encodes a nonpolyadenylated, $\sim 1.3 \mathrm{~kb}$ RNA molecule containing a 30-bp perfect match to $K$. lactis telomeric DNA. This sequence within the telomerase RNA has been demonstrated to serve as the template for telomeric repeat synthesis (McEachern and Blackburn 1995).

We have shown previously that an $\sim 300$-bp deletion of the K. lactis telomerase RNA gene (the ter1 7 ::URA3 allele) that includes the template sequence for telomeric DNA synthesis causes gradual telomere shortening with a concomitant gradual decline in the ability of $K$. lactis cells to grow (McEachern and Blackburn 1995). Here we show that the growth senescence that ensues after inactivation of the TER1 gene occurs as a direct consequence of shortening telomeres. In survivors of the initial senescence, a RAD52-dependent pathway temporarily lengthens telomeric repeat arrays and restores cellular growth surprisingly efficiently in the absence of telomerase activity. These results provide unambiguous evidence that recombination between terminally located telomeric repeat arrays can act as a functional substitute for telomerase in organisms lacking subtelomeric arrays of telomere-like repeats. We propose that a similar recombination-based mechanism is used for telomere lengthening and maintenance in immortalized human cells lacking telomerase activity or in which telomerase activity is impaired (Kim et al. 1994; Murnane et al. 1994; Bryan et al. 1995; Strahl and Blackburn 1996).

\section{Results}

Progressive growth defects in K. lactis cells lacking a functional telomerase RNA gene (TER1)

To examine the nature of the growth decline caused by deletion of the telomerase RNA gene, colony-forming ability was analyzed after disruption of the TER1 gene. Transformants carrying the ter $1 \Delta 7::$ URA3 allele initially grew indistinguishably from control TER1 transformants on the selection plates lacking uracil. However, after the first restreaking of these colonies onto rich medium, the colonies formed had discernibly rough edges. A second serial restreak produced small, very rough colonies, and by the third serial restreak, many cells failed to grow at all while most colonies that did form were extremely small and rough (Fig. 1A). A single resteak typically represents $20-25$ cell divisions.

For seven independent ter 1 clones, average colony appearance and telomere length were analyzed after successive restreaks (Table 1; Fig. 2). During the initial three passages in rich medium, telomere length in these seven ter $1 \Delta 7:$ :URA3 lines steadily decreased at a rate of $\sim 5 \mathrm{bp}$ per cell division until the telomeric repeat arrays were reduced to $\sim 5 \%-20 \%$ of their original $250-500 \mathrm{bp}$ length (McEachern and Blackburn 1995; Fig. 3), as judged by telomere fragment sizes and hybridization intensities to a telomere-specific oligonucleotide probe. This point of minimal telomere length coincided with the stage of the poorest cell growth (Table 1). Interestingly, cells from ter1 senescent colonies were generally enlarged and often attached together in small groups or strings /data not shown|. Although microcolonies formed by wild-type cells were evenly sized, smooth-edged, and round (Fig. $2 A$ ), senescent ter $1 \Delta 7::$ URA3 cells formed very abnormal microcolonies displaying enlarged cells, highly irregular colony shapes, and slow or sometimes no growth (Fig. 2B,C). The short strings of cells that often protruded from the surface of these microcolonies suggested that frequent problems in cell division cause the irregular microcolony shapes and small rough colonies of senescent ter1 strains.

\section{Some K. lactis terl cells show restored growth after the initial senescence period}

Although the great majority of ter 1 cells were inviable by around the third restreak, at this point many colonies appeared that were either large and smooth or had prominent smooth sectors. These ter 1 cells that survived beyond the period of the first few passages we have termed postsenescence survivors. We analyzed the growth properties of these postsenescence survivors by passaging the seven independent ter $1 \Delta 7:: \mathrm{URA} 3$ transformant lineages by serially restreaking representative colonies. Because at peak senescence a representative cell is dead while a representative colony may be rare but relatively healthy, this restreaking protocol repeatedly biased toward the healthier cells. As seen in Table 1, despite the senescence during the first few restreaks and occasional other periods of increased cell mortality, only one of the seven 
A 50-65 generations $\quad 80-100$ generations

TER1

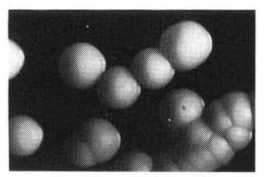

ter1

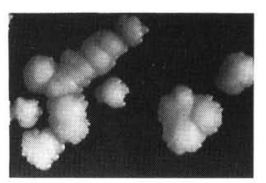

B

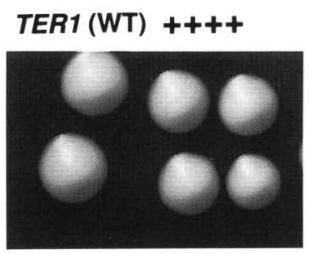

ter1 +++

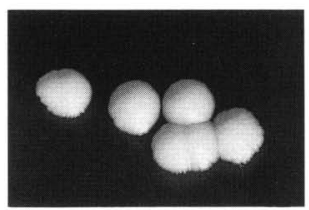

ter1 $++1 / 2$

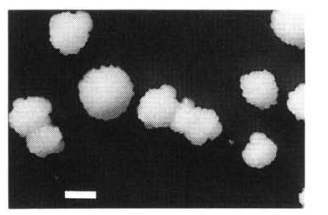

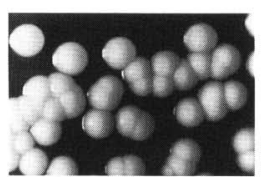

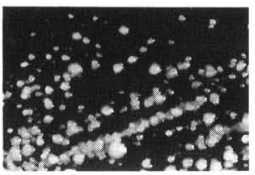

ter1 $+1 / 2$

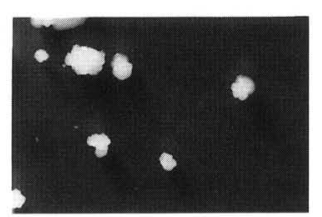

ter1 $++1 / 2$

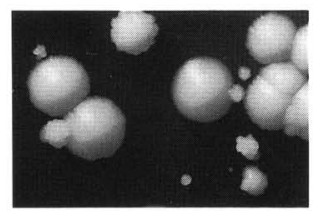

ter1 $+++1 / 2$

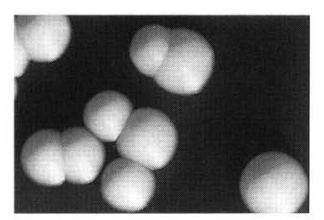

Figure 1. Colonies formed from wild-type $K$. lactis cells and from $K$. lactis cells lacking a functional TER1 gene. $|A|$ The left pair of photos show wild-type $K$. lactis and a relatively early stage of senescence of ter1 $17::$ URA $3 \mathrm{~K}$. lactis. The right pair of photos show wild-type $K$. lactis and a late stage of senescence of ter1 $\triangle 7:: U R A 3 \mathrm{~K}$. lactis. The approximate numbers of generations from the point of the deletion of the TER1 gene are given. Both photo pairs are matched for magnification and age of culture. (B) Photographs of K. lactis TER1 colonies and examples of ter1 $\Delta 7$ postsenescence survivors shown along with their assigned growth scores (see Table 1). Colonies have grown for the same period of time, $\sim 4$ days. Bar, $1 \mathrm{~mm}$.

lineages of cells followed died out entirely during the test period of $\sim 10$ serial restreaks. Over time, the growth abilities of each of the survivor lineages /typically passages $4-10$ ) fluctuated widely and did not stabilize, varying from normal colony morphology to occasionally severe senescence with the accompanying high levels of cell inviability reminiscent of the initial senescence phase. This growth pattern of the postsenescence survivors suggested that they still had the original senescence defect. However, whereas the seven TER1 deletion strains showed near-identical growth declines during the first three passages, after the appearance of postsenes-

cence survivors, the seven lineages lost all signs of synchrony (Table 1). The colony morphologies of ter 1 survivor lineages, although highly variable between and within restreaks, often were indistinguishable from those of either wild-type cells or early ter 1 cells. Figure $1 \mathrm{~B}$ shows various examples of postsenescence survivor colonies. The ability of ter 1 strains to restore growth to normal or near normal was also seen at the microcolony level. Figure 2D shows examples of microcolonies from a postsenescence survivor lineage at a point when its macrocolonies and microcolonies were both completely indistinguishable from wild type. More typically, growth was restored to extents that were intermediate between wild-type and highly senescent (Table 1). Furthermore, the episodes of growth decline in postsenescence survivors usually were milder than the initial decline (Table 1), and some lineages remained in a relatively constant state of fair to good growth for several passages. This contrasted sharply with the synchronous, rapid, and drastic decline in growth ability of cells during the initial senescence phase. It should be noted that the changes in growth rates observed in Table 1 would be partially or totally obscured in cells passaged by dilutions in liquid rather than successive restreaks down to single cells.

The indefinite growth ability of postsenescence survivors demonstrates that the TER1 gene and, by inference, telomerase activity, is not absolutely essential for growth of $K$. lactis cells.

\section{Lengthened telomeric repeat arrays in postsenescence survivors}

The telomeres in the seven independent ter $1 \Delta 7::$ URA3 template deletion lineages shown in Table 1 were analyzed by Southern blotting analysis at each serial restreak. Telomeric (top) and subtelomeric (bottom) probes were hybridized to DNA from a wild-type control lineage (Fig. 3A) and three of the ter1 lineages $(2-2,2-4$, and 1-3, Fig. 3B-D). All were followed over 8-10 restreaks. As described previously (McEachern and Blackburn 1995), the initial decline in growth was accompanied by telomere shortening (Fig. 3, B, lanes 1 and 2, and C-D, lanes 1-3). Subsequently, the telomeres in the postsenescence survivors had several striking properties. To the levels of detection possible by Southern blotting analysis, all chromosomal termini in all survivor lineages at every restreak carried telomeric repeats. If chromosome ends lacking telomeric repeats were present, some fragments would hybridize to a subtelomeric probe (the telomere-adjacent part of the $\sim 1 \mathrm{~kb}$ class of telomeres) but not to the telomeric probe. However, all telomeric fragments hybridizing to the subtelomeric probe, which detects 11 of the $12 \mathrm{~K}$. lactis EcoRI telomeric fragments, were also detected with the telo-meric repeat probe (Fig. 3B-D). Additionally, the lengths of these telomeric fragments were consistent with their still containing telomeric repeats. Together, these results suggest that even a single chromosome end without telomeric repeats is not stably maintained in $K$. lactis. 
Table 1. Growth of $\mathrm{K}$. lactis clones that carry a TER1 deletion

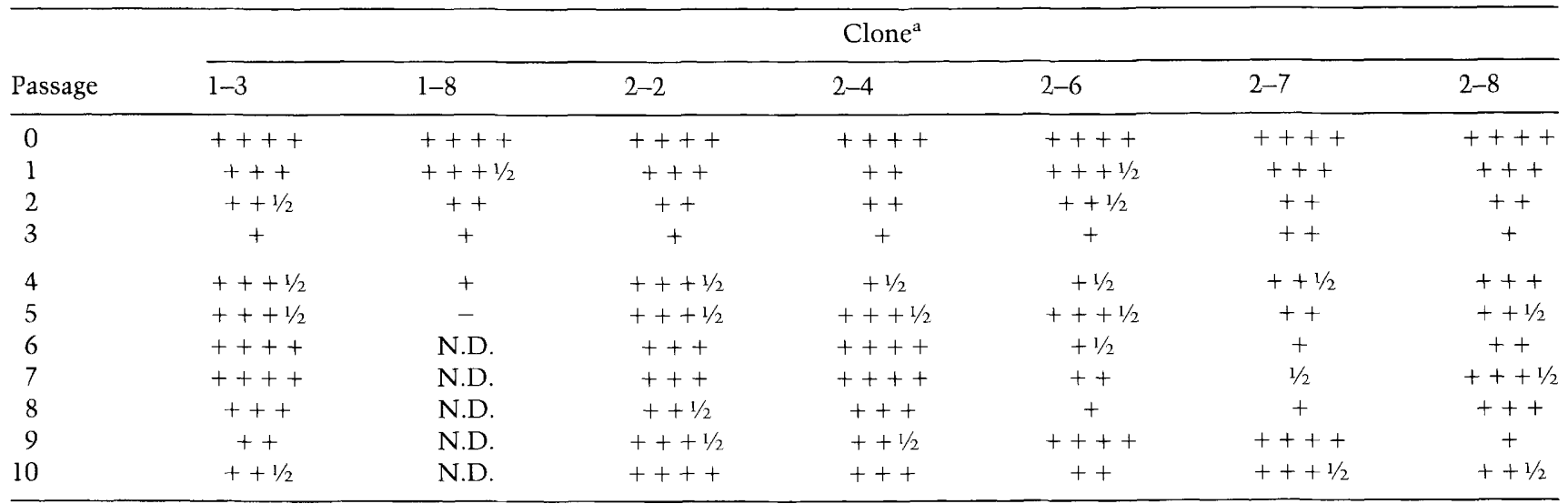

Seven independent TER1 deletion mutants were followed for 10 serial restreaks with the average colony characteristics being assessed at each passage. Each passage involved taking a representative colony from the preceeding passage and restreaking it to single cells on a YPD plate. Growth scores represent averages of the appearance of colonies for a given streak, which were often heterogeneous, especially for postsenescence survivors. Passage 0 represents the initial transformation plate; passages $1-3$ are the initial senescence period, at the end of which the large majority of cells were typically inviable; passages 4-10 involve cells considered postsenescence survivors.

a $++++\mid$ Large round colonies; $|+++|$ colonies near full size but with rough edges; $|++|$ smaller than normal colonies, very rough edges; $|+|$ very small, very rough colonies; typically with poor cell viability; $|-|$ no growth; $(1 / 2)$ intermediate phenotype, e.g., $+1 / 2$ is intermediate between + and ++ ; (N.D.) no data.

Telomeres in the postsenescence survivors were extremely variable in length compared to either wild-type or initial senescing cells. In wild-type cells, the telomeric repeat arrays are confined to a defined size range of 250-500 bp (10-20 repeats) (McEachern and Blackburn 1994), and subtelomeric sequences are also stable over time (Fig. 3A). In contrast, in all seven ter 1 lineages the telomeric fragments continually changed in size, especially after the initial senescence (Fig. 3B-D). Typically, as soon as DNA could be isolated from a postsenescence survivor, most or all of its telomeric fragments had been lengthened and were often longer than telomeres in wild-type cells. During the transition from a poorly

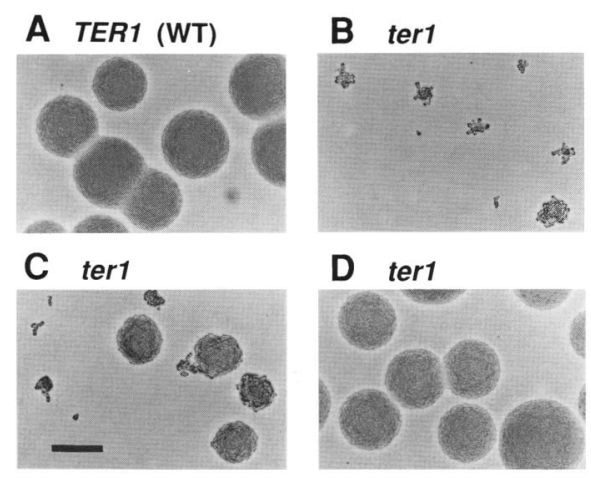

Figure 2. Photographs of TER1 and ter1 K. lactis microcolonies. Cells plated on YPD plates were grown overnight at $30^{\circ} \mathrm{C}$ prior to photography. $(A) K$. lactis TER1 strain. $(B, C) K$. lactis ter1 $\Delta 7$ strain displaying different degrees of growth senescence. (D) K. lactis ter $1 \Delta 7$ postsenescence survivor displaying normal growth. Bar, $100 \mu \mathrm{m}$. growing senescent state to a faster growing survivor state the profile of telomeric fragments was often highly complex or smeared (for examples, see Fig. 3, B, lane 3, C, lane 5 , and $\mathrm{D}$, lane 5$)$. This probably results from multiple independent survivors, each having telomeric fragments lengthened to different degrees, arising in the liquid culture for on the solid medium prior to inoculation into liquid). After isolating each individual survivor lineage by restreaking to single cells, profiles of relatively discrete and lengthened telomeric fragments emerged. However, telomeres in postsenescence survivors were still subject to the same rate $(\sim 5 \mathrm{bp} /$ cell division) of gradual shortening as during the initial senescence (this is especially apparent in Fig. 3D, lanes 6-10). These observations suggested that the telomerase deficiency of ter1 $7::$ URA3 cells was not corrected and that a mechanism very different from telomerase generates the telomeric repeats in the ter 1 postsenescence survivors.

The moderate changes in growth abilities of postsenescence survivors were not easily correlated with overall changes in their telomere profiles. However, with each of the three severest incidents of secondary senescence observed in Table 1 growth scores of + or worse after the initial senescence), telomeres on all chromosome ends were very short (data not shown). This supports the hypothesis that the instability of the lengthened telomeric repeat arrays causes the unstable growth of the survivors. As the individual arrays of telomeric repeats at different chromosome ends are highly variable in length at any one point in postsenescence survivors (see below), the typical mildness of senescence in survivors may reflect the necessity for only a minority of telomeres to be restored at any one time. This contrasts 
Figure 3. Telomeric DNA followed from initial senescence through multiple passages of postsenescence survivors in $K$. lactis strains carrying deletions of the TER1 template region. Shown are Southern blots of EcoRI-digested DNAs from wild-type $K$. lactis Y-160 (A) and three TER1 deletion clones $(B-D)$ showing clones 2-2, 2-4, and 1-3, respectively) followed over $8-10$ passages. Lanes $1-3$ of the three TER1 deletions show the initial senescence phase, as shown in Fig. 6. Lanes 4-10 show DNA from postsenescence survivors. Lane $0(C, D)$ shows DNA from wild-type clones as controls for normal telomere length. (Top) Hybridization to a 25nucleotide telomere probe (KLAC 1-25, $49^{\circ} \mathrm{C}$ ); (bottom) the same filters that have been stripped and reprobed with a sub-telomeric probe (see Materials and methods for details). All 12 telomeres are visualized by the telomeric probe. The dark band at $\sim \mathrm{l} \mathrm{kb}$ is composed of seven telomeres.

The subtelomeric probe does not hybridize with exactly the same intensity to each telomeric fragment that it detects. Pairs of arrows indicate examples of telomeric fragments that display a high ratio of telomeric/subtelomeric signal when long relative to when short. Lane 4 of $D$ is underloaded. Size markers are indicated (in $\mathrm{kb}$ ).

with the original senescence phase, when all telomeres synchronously become critically short.

Evidence that extra telomeric repeats accounted for the elongation of telomeric restriction fragments in postsenescence survivors came from two main lines of data. First, the elongated telomeric restriction fragments of postsenescence survivors sometimes hybridized very strongly with a telomeric probe (Fig. 3, top panels) compared with the subtelomeric probe (Fig. 3, bottom panels), when normalized against the intensities of the ethidium bromide-stained gel lanes (data not shown). Examples of such telomeres are marked with sets of arrows in Figure 3, B and D. Second, Bal 31 nuclease digestions were performed in parallel with DNA from a wild-type
$K$. lactis strain (Fig. 4A) and from a template deletion strain in the process of producing postsenescence survivors (Fig. 4B; the DNA sample used is the same as in Fig. $3 \mathrm{~B}$, lane 3). In the wild-type strain all the telomeres lost the hybridization signal with the telomeric repeat probe at the same time point in the digestion, indicating that the length of telomeric repeat arrays is similar on all chromosomes. In contrast, in the emerging postsenescence survivor, hybridization to the telomeric probe persisted on some fragments longer than on others. The elongated telomeric fragments visible in Figure $4 \mathrm{~B}$ (marked with dots) were not visible in the preceding culture of senescing cells (Fig. 3B, cf. lanes 2 and 3). In a more extensive Bal 31 digestion (data not shown), one
Figure 4. Bal 31 digestion time courses of telomeric DNA from wild-type $K$. lactis $(A)$ and a postsenescence survivor $(B)$. DNAs prepared from $K$. lactis strain $7 \mathrm{~B} 520$ and from the TER1 deletion strain $2-2$ (passage 3 of Fig. 3B) were digested for varying lengths of time (shown in minutes above each lane) with Bal 31 exonuclease, followed by digestion with EcoRI and electrophoresis through agarose. Hybridization was with a telomeric oligonucleotide (KLAC $\left.1-25,60^{\circ} \mathrm{C}\right)$. The absolute rate of digestion was greater for the DNA from the wild-type strain. Dots indicate the positions of telomeric fragments that were not present in the preceding passage of this transformant (Fig. 3B, cf. lanes 2 and 3). The asterisk indicates a fragment that apparently has $\sim 2 \mathrm{~kb}$ of telomeric repeats (see text). Size markers are indicated (in kb).

\section{A}

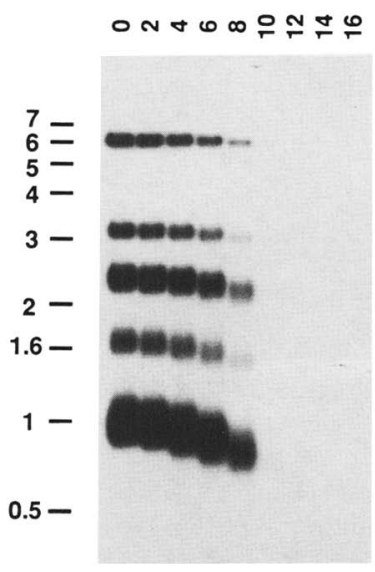

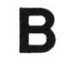

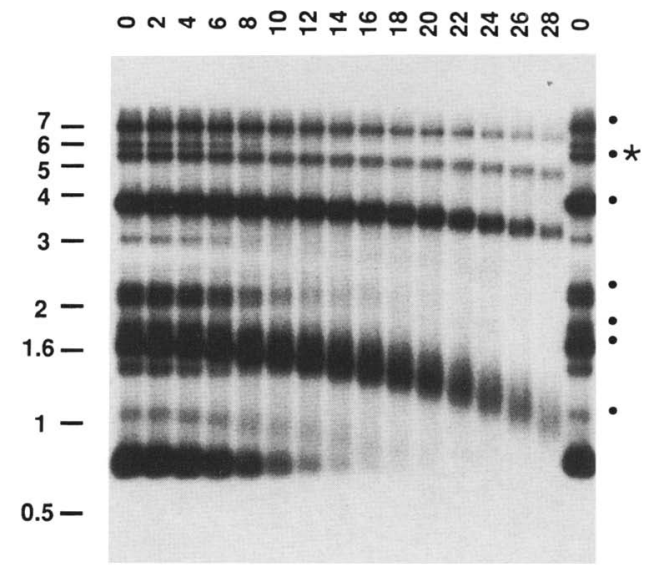


such new telomeric fragment (Fig. 4B, asterisk) was shortened by $\sim 2 \mathrm{~kb}$ before its telomeric hybridization disappeared. If this $\sim 2$-kb stretch of DNA was composed entirely of telomeric repeats, the relatively weak hybridization signal of this band indicates that it was present in only a fraction of the cells in the population. Consistent with this interpretation, this band was not present after the next passage of this survivor lineage (which, like each passage, was regrown from a single colonyl.

These results showed that changes in the number of telomeric repeats account for the majority of the telomeric restriction fragment length changes occurring in postsenescence survivors. Less frequently, changes in subtelomeric sequences were observed. For example, in Figure $3 \mathrm{C}$, the disappearance of the largest telomeric EcoRI fragment $(\sim 6 \mathrm{~kb})$ after the fifth passage cannot be accounted for solely by shortening the telomeric repeat arrays. As discussed below, subtelomeric gene conversion may have led to formation of a telomere with an EcoRI site nearer to the terminus.

\section{Loss of telomeric repeats, rather than absence} of telomerase activity per se, leads to senescence in ter1 strains

The gradual onset of cell growth problems following loss of TER1 function suggested that they are caused by shortening telomeres. However, these results did not exclude the possibility that the absence of telomerase activity per se contributed to the growth abnormalities. For example, telomerase action might be required during each cell cycle to form a specific telomeric terminal structure, such as the $3^{\prime}$ single-stranded tails known to exist at telomeres in some eukaryotes (for review, see Henderson 1995). To test this possibility with cells that had not experienced a strong selective pressure for growth, the TER1 gene was deleted from a $K$. lactis strain containing telomeres two to three times normal length. This state of the telomeres was established by constructing a strain that first contained, at the normal chromosomal locus of the TER1 gene, two different mutated TER1 genes separated by an integrated plasmid containing a URA3 gene: the ter $1 \triangle 7$-deleted form of the TER1 gene (identical to ter 1 7::URA3 except it lacked a URA3 gene insertion within the TER1 coding sequence), and the template mutation ter1-AA, which is functional but can cause telomeres to be moderately elongated in some circumstances (see Materials and methods; McEachern and Blackburn 1995). 5-FOA-resistant strains were selected that had "looped out" the integrated plasmid, leaving either the ter1-AA gene or the ter $1 \Delta 7$ gene. The growth of six of the eight newly constructed ter $1 \Delta 7$ strains, all of which initially had elongated telomeres but now lacked a functional TER1 gene, was like wild type for two to five passages on YPD medium (Table 2). Over several passages, the telomeres of these ter $1 \Delta 7$ strains derived from the ter $1-A A /$ ter $1 \Delta 7$ parent gradually shrank (Fig. 5). No growth problems occurred until the telomeres had shortened considerably. In contrast, six of six new control ter $1 \Delta 7$ strains derived from a similar parental strain with a wild-type TER1 gene, and therefore initially containing normal length telomeres, showed typical signs of senescence at the colony level by the first passage (data not shown). Hence, starting with telomeres at or above normal length can prevent or delay the growth defects that occur in a ter $1 \Delta 7 \mathrm{~K}$. lactis strain. These results, together with the observation that ter1 postsenescence survivors can at least temporarily grow indistinguishably from wild-type $K$. lactis cells (Table 1 ), suggest that normal cell division requires neither telomerase activity at each cell generation nor any telomerase-dependent terminal structure.

Table 2. Growth of ter $1 \Delta 7$ clones derived from a strain with elongated telomeres (ter1-AA)

\begin{tabular}{|c|c|c|c|c|c|c|c|c|}
\hline \multirow[b]{2}{*}{ Passage } & \multicolumn{8}{|c|}{ Clone $^{a}$} \\
\hline & $\mathrm{AA} \Delta \mathrm{l}$ & $\mathrm{AA} \Delta 2$ & $\mathrm{AA} \Delta 4$ & $\mathrm{AA} \Delta 5$ & $\mathrm{AA} \Delta \overline{7}$ & $\mathrm{AA} \Delta 10$ & $\mathrm{AA} \Delta 11$ & $\mathrm{AA} \Delta 12$ \\
\hline 0 & ++++ & ++++ & ++++ & ++++ & $+++t$ & ++++ & ++++ & ++++ \\
\hline 1 & ++++ & $+t+t$ & ++++ & ++++ & ++++ & ++++ & ++++ & ++++ \\
\hline 2 & ++++ & +++ & ++ & ++++ & ++++ & ++++ & $++t+$ & ++++ \\
\hline 3 & $+++1 / 2$ & ++ & +++ & ++++ & $+++1 / 2$ & ++++ & $+++1 / 2$ & $+++1 / 2$ \\
\hline 4 & +++ & +++ & ++ & +++ & $++1 / 2$ & ++++ & $+++1 / 2$ & $+++1 / 2$ \\
\hline 5 & $++1 / 2$ & $++1 / 2$ & $++1 / 2$ & ++ & ++ & ++++ & +++ & +++ \\
\hline 6 & $+++t$ & ++ & $++1 / 2$ & $++1 / 2$ & $++t$ & +++ & ++ & ++ \\
\hline 7 & ++++ & $+1 / 2$ & ++ & $++1 / 2$ & $++1 / 2$ & $++1 / 2$ & $++1 / 2$ & +++ \\
\hline 8 & ++++ & $++1 / 2$ & ++ & $++1 / 2$ & $++1 / 2$ & $++1 / 2$ & + & +++ \\
\hline 9 & ++++ & $+1 / 2$ & + & $++1 / 2$ & + & $++1 / 2$ & $+1 / 2$ & $++1 / 2$ \\
\hline
\end{tabular}

Eight independent ter1 $\Delta 7$ mutants were followed for nine serial restreaks with the average colony characteristics being assessed at each passage. Each passage involved restreaking a representative colony from the preceding passage YPD medium. Growth scores represent averages of the appearance of colonies for a given streak, which were often heterogeneous, especially for postsenescence survivors. Pasage 0 represents the initial transformation plate. Growth senescence is delayed relative to ter $1 \Delta 7$ clones derived from a strain with telomeres of wild-type length. (see Materials and methods for details.)

${ }^{\text {aScoring }}$ as in Table 1. 

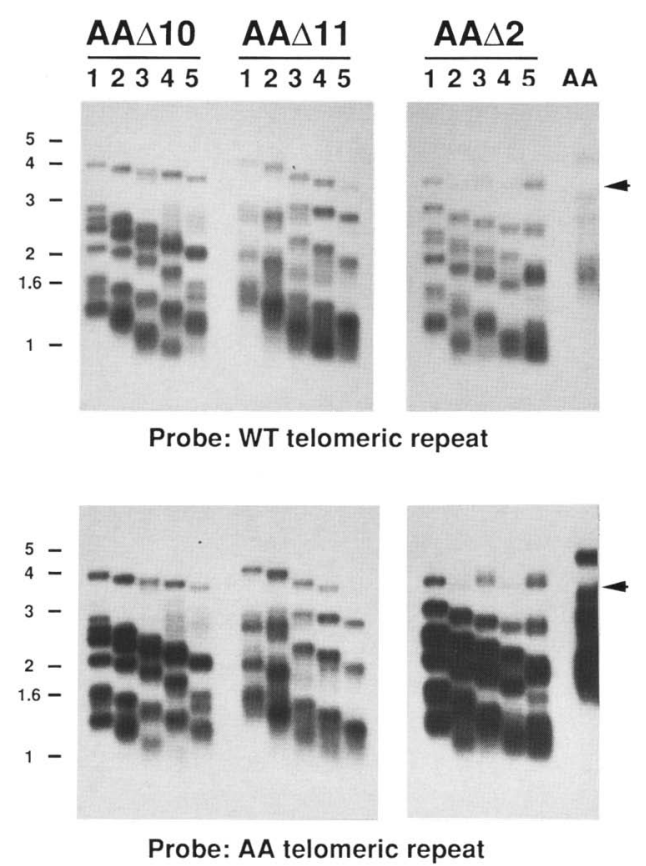

Figure 5. Southern blot showing telomere shortening in three ter $1 \Delta 7$ lineages derived from ter $1-A A /$ ter 1$\lrcorner 7$ cells with elongated telomeres. DNA samples from the five initial passages of these lineages are shown digested with EcoRI and hybridized to each of two 14 nucleotide probes specific to either wild-type $K$. lactis telomeric repeats $\left(\right.$ top, $\left.40^{\circ} \mathrm{C}\right\rangle$, or to $K$. lactis AA mutant repeats (bottom, $38^{\circ} \mathrm{C}$. As a result of the manner of the construction of the parental strain, these ter 137 lineages, like the ter1-AA parent, are expected to contain wild-type telomeric repeats in the most internal region of the telomeric arrays and AA mutant repeats in the more external region of the arrays. The more rapid loss of AA repeats can be seen in some instances. The lane marked AA contains a DNA sample from a ter1-AA strain to show telomere length prior to deletion of the ter1-AA allele. Length and pattern of telomeric fragments in a wild-type $K$. lactis $7 \mathrm{~B} 520$ strain (original parent of these strains) can be seen in lane W of Fig. 7. A longer exposure of the K. lactis AA hybridization is shown for clone AA $\Delta 2$. Arrows indicate the position of a short telomere in the AA $\Delta 2$ clone that undergoes two succesive cycles of shortening and elongating during the time course shown. Size markers are indicated (in kb).

Two of the eight ter1 $\Delta 7$ lineages derived from the ter1-AA/ter1 $\Delta 7$ background (clones AA $\Delta 2$ and AA $\Delta 4$ ) displayed visibly senescent colonies by the second YPD passage. Interestingly, from the point of their creation, both contained a single abnormally short telomeric array, as judged by its restriction fragment length, relatively low hybridization to a telomeric probe, and lack of protracted shortening over time (Fig. 5; data not shown). During the first five passages, this fragment (the largest telomeric restriction fragment of clone $\mathrm{AA} \Delta 2$, see arrow) underwent two cycles of shortening followed by modest lengthening (Fig. 5). The early signs of senescence in these two lineages suggests that a single abnormally short telomere may be sufficient to cause detectable growth problems.

\section{Postsenescence survivors are generated by a RAD52-dependent pathway}

To investigate the mechanism of elongation of telomeric repeat arrays in ter1 postsenescence survivors, we tested whether the RAD52 gene is required to generate survivors. In $S$. cerevisiae, the RAD52 function gene is essential for most homologous recombination, both mitotic and meiotic (Petes et al. 1991). K. lactis ter1 rad52 strains were constructed by disruption of the K. lactis RAD52 homolog (Milne and Weaver 1993). A ura3 ter1 postsenescence survivor was transformed with a restriction fragment carrying a URA3-disrupted rad52 gene (see Materials and methods). The resulting $K$. lactis ter 1 rad52 strains behaved markedly differently from strains carrying only the ter 1 deletion. Initially, the ter 1 rad52 strains grew slowly and formed irregular colonies like those of ter 1 RAD52 strains. However, these colonies never produced the fast-growing sectors characteristic of senescent ter1 RAD52 strains (Fig. 6), and after one or two restreaks, the ter 1 rad52 cells almost invariably failed to grow further (the rare exceptions are described below).

The greatly diminished production of postsenescence survivors by ter 1 rad52 strains indicated that recombinational repair is the major mechanism for generating ter1 survivors. However, faster growing ter1 rad52 survivors did emerge at a very low frequency, which was estimated at no more than 1 in $10^{6}$ cells per generation, a rate at least two orders of magnitude below that in ter 1 RAD52 strains. Within a few streaks these ter1 rad52 survivors essentially lost the ability to grow further, after which faster growing secondary survivors appeared, again at the very low frequencies seen after their initial senescence phase. In the ter 1 rad52 postsenescence survivors, the restoration of cell growth was accompanied by partial restoration of telomere array lengths, sometimes up to near wild-type lengths (Fig. 7). As in ter1 RAD52 survivors, the lengthened telomeres of ter1
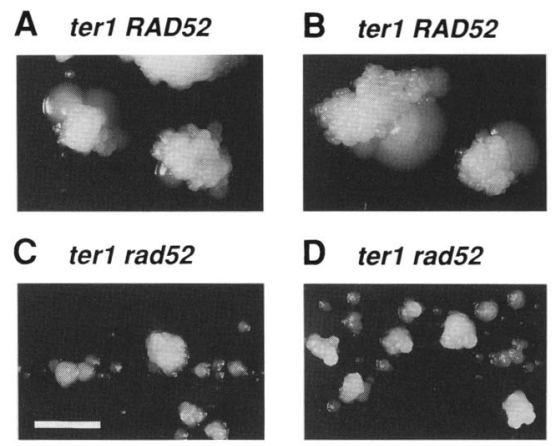

Figure 6. Photographs of highly senescent ter1 RAD52 and ter1 rad52 K. lactis strains. $(A, B)$ Photographs of 7 -day-old senescent ter1 RAD52 colonies with fast-growing sectors emerging from them. A significant fraction of highly senescent ter1 $R A D 52$ colonies are observed to produce such sectors. $(C, D)$ Photographs of examples of 14-day-old senescent ter 1 rad52 colonies that do not produce fast-growing sectors. Bar, $1 \mathrm{~mm}$. 


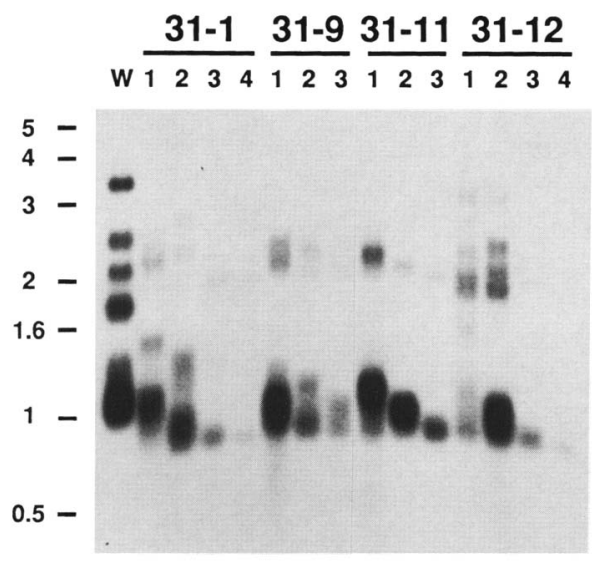

Figure 7. Southern blot of telomeric fragments in ter1 rad52 $\mathrm{K}$. lactis strains. DNA samples from wild-type (lane $\mathrm{W}$ ) and four independent ter 1 rad52 postsenescence survivors are shown digested with EcoRI and hybridized to a wild-type telomeric oligonucleotide probe (K. lactis $1-25$ at $\left.50^{\circ} \mathrm{C}\right)$. DNA from three or four consecutive passages of each double mutant strain are shown. Time points with the shortest telomeres correspond to the passages that displayed the poorest growth. A simplified pattern of telomeric fragments in the mutant strains arose in a ter1 RAD52 parent, which presumably reflects the outcome of telomeric gene conversion events, as described in the Discussion. Size markers are indicated (in $\mathrm{kb}$ ).

rad52 survivors were still subject to gradual shortening and had telomere lengths that were at a minimum at the time of minimum growth ability. Also like ter1 RAD52 survivors, ter 1 rad52 survivors that underwent a secondary severe growth decline (growth score of + or worse) did not display any apparent improvement in their growth restoration ability relative to cells from the initial senescence (data not shown). This suggests that growth restoration in both cases is recombinational and not attributable to suppressor mutations. This conclusion is further supported by the observation that ter 1 postsenescence survivors that have had their telomeres restored by reintroduction of a wild-type TER 1 and then had it deleted again, show growth senescence and telomere shortening that is indistinguishable from first-time deleted strains (J. Roy and E. Blackburn, unpubl.). As $S$. cerevisiae rad52 mutations do not completely abolish homologous recombination (Petes et al. 1991), it is likely that homologous recombination events also generate the rare postsenescence survivors in rad52 ter1 strains.

\section{Discussion}

Here we have shown that in the yeast $K$. lactis, the growth senescence caused by absence of a functional telomerase is the result of shortened telomeres. Our results also show that homologous recombination can serve as a relatively efficient substitute for telomerase for maintaining telomeric repeat arrays at chromosome termini. To explain these findings, we propose the model shown in Figure 8 . Briefly, this model states that the shortening of telomeres occurring in ter 1 strains causes them to lose their "capping" function and to be treated by $K$. lactis cells as DNA double-strand breaks (DSBs). That in turn leads to cell cycle arrest and induced gene conversion at telomeres that is often sufficient to restore the lengths of telomeric repeat arrays to wild type or greater lengths. This model combines the findings reported here on $K$. lactis ter 1 strains with known properties of DSB repair in $S$. cerevisiae.

Evidence in a number of systems indicates that telomere functions, including capping, require only the arrays of terminal telomeric repeats as the cis-acting DNA sequences (for review, see Cooke 1995). It would therefore be expected that complete loss of telomeric repeats from a chromosome end would lead to that end behaving

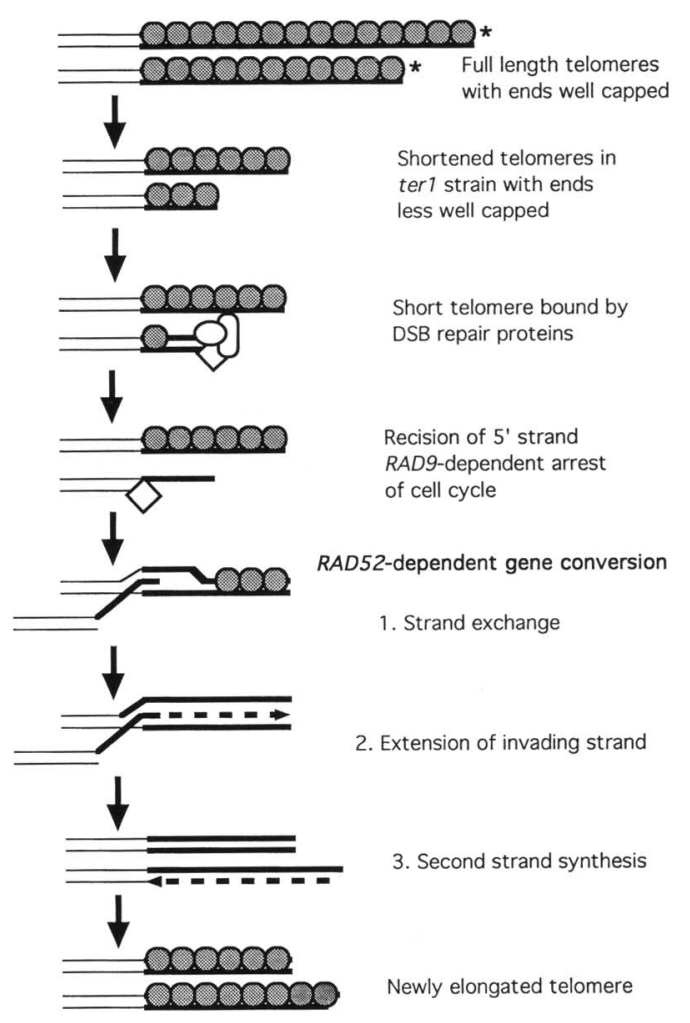

Figure 8. Model for telomeric repeat array lengthening in ter1 strains. Chromosome ends are depicted as double lines with hypothetical double-strand telomere-binding protein molecules (shaded circles) shown bound to individual 25-bp telomeric repeats (shown as thick lines in the absence of bound protein). Full-length telomeric repeat arrays, marked with asterisks, are effectively fully capped by being bound by one or more type of telomere-binding proteins and therefore are resistant to being acted upon by DSB repair enzymes. As telomeres in ter1 strains gradually shorten, capping function gradually decreases and the chances of telomeres being mistaken for DSBs becomes high. Processing of telomeric ends by DSB repair enzymes produces a $3^{\prime}$ single-strand overhang that can invade a longer duplex telomere and initiate a gene conversion event, similar to those thought to occur at DSBs at chromosome internal positions (Petes et al. 1991; Haber 1995). Staggered alignment of telomeric repeats between the recombining DNA molecules could result in the gene conversion creating a telomeric repeat array longer than the array being templated, as suggested by the diagram. 
like a DSB. In S. cerevisiae, the favored general pathway for the repair of DSBs involves homologous recombination, with an unbroken homologous sequence being used as the template for repair of the disrupted sequence, resulting in gene conversion events (Petes et al. 1991; Haber 1995). The first stage of this recombinational repair involves $R A D$ 9-dependent cell cycle arrest (Weinert and Hartwell 1988; Schiestl et al. 1989|, which can be caused by even a single DSB in a nonessential plasmid or chromosome (Bennett et al. 1993; Sandell and Zakian 1993). Although we have not directly demonstrated the occurrence of cell cycle arrest, the frequent inviability, enlarged size, and cell division defects of senescing ter 1 cells are all properties highly reminiscent of $S$. cerevisiae cells that have undergone cell cycle arrest as a result of a DSB (Weinert and Hartwell 1988; Bennett et al. 1993).

In $S$. cerevisiae, DSB repair involves recision of the $5^{\prime}$ end, creating a $3^{\prime}$ single-stranded tail that can invade an intact, homologous heteroduplex and initiate a gene conversion event (Haber 1995). Given the relatedness of $S$. cerevisiae and $K$. lactis, it is likely that DSB repair processes will be very similar in these yeasts. The model shown in Figure 8 predicts that gene conversion events will occur in telomeric regions. The subtelomeric changes observed in ter 1 strains but not in isogenic wildtype TER1 strains are most readily explained as gene conversion events. Because 11 of 12 telomeres in the $K$. lactis strains used in this study share subtelomeric homology with each other, gene conversion events initiated at an uncapped telomere would be expected to often extend some distance into the subtelomeric region. Additional strong evidence for gene conversions near telomeres comes from the finding of high frequencies of subtelomeric gene conversion rates in certain TER $1 \mathrm{~K}$. lactis mutants that have progressively shortening or stably shortened telomeres (M.J. McEachern and E.H. Blackburn, in prep.).

Four important predictions of the model shown in Figure 8 are (1) Complete loss of telomeres will be incompatible with growth; (2) gene conversion events at telomeres should be an expected consequence of functionally uncapped telomeres; (3) cell cycle arrest should occur as a result of telomere shortening; and (4) loss of capping function could occur even when some telomeric repeats still remain at a chromosome end. Each of these predictions is borne out by our data.

By Southern blotting we did not detect chromosome ends lacking telomeric repeats in postsenescence survivors, strongly suggesting that growth of $K$. lactis cells requires the presence of some telomeric repeats on all chromosome ends. We cannot rule out, however, that a chromosome end without telomeric repeats might persist for a few generations as seen in S. cerevisiae (Sandell and Zakian 1993). The types of recombinational events that we have observed are also consistent with the chromosome ends in ter1 strains retaining some telomeric repeats at the time of their elongation. First, the single telomere lacking subtelomeric sequence homology with the other 11 chromosomal ends was capable of RAD52dependent elongation. Second, chromosomal ends in ter1 strains often lengthened their telomeric repeat arrays to sizes greater than any previously present in that cell. Third, the telomeric and subtelomeric alterations sometimes occurred in ter 1 deletion strains even before telomeric arrays had become critically short. An example of this was visible in previous work with ter1 deletion strains (McEachern and Blackburn 1995; Fig. 3E, passage 1 of right-most deletion strain), where it was observed that two telomeric fragments in one ter 1 strain were elongated to greater than wild-type lengths, even while the other telomeres had become shortened. Bal 31 exonuclease digestion experiments confirmed that these were elongated telomeres $\sim 150 \mathrm{bp}$ longer than wild-type telomeres (data not shown). We propose that the recombinational events occurring early during the initial senescence period are like those producing elongated telomeres in postsenescence survivors in being promoted by loss of capping. Notably, they occur prior to massive cell death or any strong selection for survival. Overall, the types of recombinational events that we have observed imply that telomere lengthening in ter 1 strains sometimes involves recombination between the residual telomeric repeats themselves, as shown in Figure 8. Similar recombination between telomeric repeat arrays was proposed previously for $S$. cerevisiae, although this was RAD52-independent (Walmsley et al. 1984; Wang and Zakian 1990|. We have termed recombinational processes that can indefinitely maintain telomeres within a cell population and are induced by loss of telomere capping function telomere cap-prevented recombination or telomere CPR.

Telomere CPR in senescent ter $1 \mathrm{~K}$. lactis cultures does not typically begin until all telomeres in the cell have shortened to below $100 \mathrm{bp}$, yet the postsenescence survivors frequently emerge containing telomeres many times that length. Because gene conversion events of the sort proposed in Figure 8 cannot generate a telomere more than double the length of the longest telomere in the cell, an especially proficient recombinational means is necessary to explain the degree of telomere elongation observed in the survivors. Conceivably, factors that could be involved in such telomeric hyper-recombination include induced synthesis of recombinational repair proteins, or a prolonged cell cycle arrest in the presence of many uncapped ends, allowing time for multiple rounds of gene conversions to occur on a given telomeric end in a single cell cycle. If this preceded re-establishment of a cap structure, it could potentially elongate telomeric arrays of even wild-type length that otherwise would not be likely to undergo recombination. We note that once a single telomere has been elongated, it could be used as a template to elongate many other telomeres in the cell.

Despite occurring through very different mechanisms, both telomerase and telomere CPR appear to lengthen telomeric repeat arrays somewhat stochastically and are probably induced by telomeric arrays dropping below a threshold size (Fig. 8; McEachern and Blackburn 1995). However, recombination cannot be a major contributor to telomere maintenance in wild-type $K$. lactis cells, be- 
cause massive cell death occurs within 50-100 cell divisions after deletion of the TER1 gene. Neither the large increases in telomere length, nor the sporadic subtelomeric gene conversions that characterize recombinationmediated telomere maintenance, are observed in wild type cells. Unlike telomerase-mediated elongation, telomere CPR occurs detectably only when telomeric repeat arrays are short enough to arrest cell growth and not frequently enough to prevent periods of massive cell death. Thus, telomere CPR can maintain telomeres quite efficiently at the level of large cell populations but often fails at the level of the individual cells. Furthermore, the telomeric repeat arrays created by recombination in ter 1 cells have much greater size ranges than those in cells with functional telomerase. This finding suggests that the mechanisms that normally regulate telomere lengths between the usual narrow bounds do not operate in the absence of telomerase.

The initial phenotypes of $K$. lactis ter 1 deletion strains resemble those of $S$. cerevisiae est 1 and $t / c 1$ mutants (Lundblad and Szostak 1989; Singer and Gottschling 1994) in consisting of gradual telomere loss, gradual cellular senescence, and postsenescence survivors. The est 1 postsenescence survivors, until now the only ones characterized (Lundblad and Blackburn 1993), also arise in a RAD52-dependent manner and hence can be considered to be another example of telomere CPR. However, in contrast to $K$. lactis ter 1 postsenescence survivors, est1 survivors amplify the large subtelomeric $Y^{\prime}$ sequences, including neighboring internal telomere-like $T_{1-3}$ tracts, whereas the terminal telomeric arrays themselves remain short (Lundblad and Blackburn 1993). These differences between $S$. cerevisiae and $K$. lactis most likely stem from the different subtelomeric sequence arrangements in the two species. Chromosome ends of $S$. cerevisiae, unlike those in other organisms that have been characterized, generally contain two or more arrays of telomeric $\mathrm{TG}_{1-3}$ repeats, one at the very terminus and others separated from the terminus by one or more tan$\operatorname{dem} \mathrm{Y}^{\prime}$ elements that are each several kilobases in length and separated in turn from each other by telomeric $\mathrm{TG}_{1-3}$ repeat tracts. The massive amplifications of $\mathrm{Y}^{\prime}$ elements and their adjoining $\mathrm{TG}_{1-3}$ arrays (Lundblad and Blackburn 1993) in est1 deletion survivors are thought to arise as a by-product of gene conversion events that bring the formerly internal telomere-like arrays to the chromosome ends, where they can function as telomeres. As $K$. lactis lacks subtelomeric arrays of telomere-like repeats, our results demonstrate that subtelomeric reservoirs of telomeric repeats are not required for telomere CPR.

In principle, the telomeres from $K$. lactis and other yeast species with large telomeric repeats might behave quite differently from telomeres composed of short repeats. However, given the presence of both long telomeric repeats and short "typical" telomeric repeats among a related group of yeast species (McEachern and Blackburn 1994), and that both types are synthesized by telomerase, it is unlikely that they differ greatly in function. Conceivably, heterogeneous telomeric sequences could be less efficient at the initial strand invasion step than homogeneous repeat arrays, but how telomeric repeat size and sequence might affect telomere CPR is currently unknown.

The mechanism by which telomeres are capped remains unclear. Our results suggest that telomere capping in K. lactis may require most or all of the 250-500 bp of the telomeric repeat array for full function but does not otherwise address the nature of the cap. One probable trans-acting cap component is the Rapl protein, a multifunctional protein that binds the double-stranded telomeric repeats in S. cerevisiae (Berman et al. 1986; for review, see Fang and Cech 1995; Shore 1995; Zakian 1995) and K. lactis (A. Krauskopf and E. Blackburn, in prep.). Another potential cap component is the Cdcl3 protein, which when mutated in $S$. cerevisiae, causes very long 3 ' single-stranded overhangs to appear at telomeres and RAD9-dependent, $\mathrm{G}_{2}$ cell cycle arrest (Garvik et al. 1995). These are the expected phenotypes if the telomere capping function was lost and telomeres were treated like DSBs. Other hypothetical capping components include telomere end-binding proteins and DNA G-quartet structures. The former are known to occur in ciliated protozoans (Fang and Cech 1995), and the latter have been shown to occur in vitro with a variety of G-rich telomeric sequences (Henderson 1995).

Telomerase activity has been reported in most human cancers studied to date but not in most normal somatic cells (Morin 1989; Prowse et al. 1993; Shay et al. 1993; Counter et al. 1994; Klingerhutz et al. 1994). The shortening of telomeres with age in some somatic tissues (Harley et al. 1990; Hastie et al. 1990; Lindsey et al. 1991; Allsopp et al. 1992) suggested the hypothesis that telomere shortening in somatic cells may limit their cell division capacity. Progression of a cancer might then depend on cells acquiring the ability to restore and maintain telomeric repeat arrays. At least two aspects of our $K$. lactis work have important implications for understanding telomere behavior in human cells. First, failure of telomere capping even when some telomeric repeats still remain at a chromosome end suggests that the same could occur in mammalian cells. This might explain why growth arrest of senescent somatic cells in vitro occurs with appreciable telomeric repeat hybridization signal still present at chromosome ends (Counter et al. 1992) and why telomere-telomere fusions (telomere associations) often occur with telomeric repeats still being detectable at the fusion points (Pezzolo et al. 1993; Saltman et al. 1993). Second, we have shown that recombination is a relatively efficient means of maintaining telomeric repeat arrays in the absence of telomerase. Hence, we propose that recombination is the mechanism of telomere maintenance in immortalized human cell lines lacking detectable telomerase (Kim et al. 1994; Murnane et al. 1994; Bryan et al. 1995; Rogan et al. 1995). This possibility is clearly of importance for potential anticancer drugs that target telomerase. Further investigation of the causes and consequences of telomere capping failure in $K$. lactis should illuminate this and other aspects of human telomere function. 


\section{Materials and methods}

\section{Construction of terl strains}

The telomere homology region was deleted from within a 4-kb $B a m H I-X b a I$ subclone (pTER1-BX) by linearizing at a unique HpaI site $\sim 200$ bp downstream of the telomere homology, digesting with Bal 31 nuclease for different lengths of time, and ligating in the presence of $B g l I I$ linkers. Deletion clones were screened for the absence of the telomere homology and the presence of a new BglII site. A clone (pTER1-BXter147) that had both of these properties then had an $\sim 1.1-\mathrm{kb}$ BamHI-BgIII fragment containing the $S$. cerevisiae URA3 gene from pMH3 (Hollingsworth and Byers 1989) inserted into the BglII site to create the ter1 $10::$ URA3 allele [referred to previously as ter1 $\Delta 7$ (McEachern and Blackburn 1995)]. The resulting plasmid, estimated to have $\sim 300$ bp deleted from it, was then cut with $\mathrm{Xbal}$ and $B a m H I$ to excise the URA3-interrupted ter1 sequence, and this was then transformed into the Ura3 ${ }^{-} K$. lactis strain 2366-6 (Y-160) (I. Herskowitz, University of California, San Francisco) to create the ter $1 \Delta 7::$ URA3 transformants shown in Figure 3 and Table $1 . K$. lactis transformation was carried out by electroporation, as was done for $S$. cerevisiae (Becker and Guarente 1991).

$K$. lactis transformants shown in Figures 1 and 3 containing the ter1 17 allele (lacking a URA3 insertion into TER1) were created by transforming $K$. lactis strain $7 \mathrm{~B} 520$ (Ura ${ }^{-}$, Trp , His $^{-}$) (Wray et al. 1987) with uncut pTER1-BX-UAter1 1 (containing URA3 adjacent to TER1 sequences|. Ura3 ${ }^{+} K$. lactis transformants with the plasmid integrated at TER1 (and containing one copy of wild-type TER1 and one copy of ter1 147 ) were identified. One such clone was plated onto 5-FOA media (Boeke et al. 1984) to select for Ura3 ${ }^{-}$clones that had looped out the integrated plasmid. Clones retaining either wild-type TER1 or ter $1 \Delta 7$ were identified by Southern blotting, and Ter $1^{+}$ clones generated in this way served as the TER1 controls for Figures 1 and 3.

The ter1 17 clones shown in Table 2 and Figure 5, which began with elongated telomeric arrays, were derived in a similar loop in/loop out process done twice in succession. After creating a Ura3- ter $1 \Delta 7$ clone derived from 7B520 in the first loop in/loop out, the resulting senescing cells were transformed with uncut $\mathrm{p} T E R$ 1-BX-UAter $1-A A$. The ter1-AA allele is a double base pair change in the template region that has no effect on telomere length when replacing wild-type TER 1 but that creates moderately elongated telomeres when replacing a TER1 deletion (McEachern and Blackburn 1995). The telomere lengthening that occurs in the latter instance appears to be attributable to a greater degree of replacement of the wild-type telomeric repeats present more internally in the telomeric repeat arrays (McEachern and Blackburn 1995). Placing the ter147/ter1-AA heteroallelic strain onto 5-FOA medium selected for plasmid loop outs and Ura3 strains containing either ter $1 \Delta 7$ or ter $1-A A$ were identified by Southern blotting.

\section{Construction of $\mathrm{K}$. lactis terl rad52 strains}

A first attempt to produce ter 1 rad52 $\mathrm{K}$. lactis strains involved transforming ura3 ter 1 cells that were at the earliest possible state of senescence with a restriction fragment carrying a $U R A 3$-disrupted rad52 gene. None of the transformants recovered from this experiment were the desired double mutant strain. As we suspected that a ter 1 rad52 strain might be unable to survive past the initial senescence period, we repeated the transformation with a ura 3 ter 1 postsenescence survivor, reasoning that elongated telomeres in a survivor lineage might be more likely to permit the isolation of the desired double mutant. Through this means we were able to successfully construct and identify ter 1 rad52 $\mathrm{K}$. lactis strains. The RAD52 gene disruption was made by inserting the $B a m H I-B g I I I$ restriction fragment from pMH3 containing the URA3 gene into a BamHI site in the $5^{\prime}$ part of the $K$. lactis $R A D 52$ open reading frame. A fragment containing this disruption was then transformed into K. lactis ter1 cells.

\section{DNA analysis and microscopy}

$K$. lactis DNA was prepared from cells grown at $30^{\circ} \mathrm{C}$ in liquid YPD medium. The DNA gels shown were $0.8 \%$ agarose and electrophoresed overnight. Southern blotting was done onto Hybond $\mathrm{N}+($ Amersham $)$ according to the recommendations of the manufacturer, and DNA was cross-linked to the membrane using a Stratalinker 1800 (Stratagene). All hybridizations were carried out according to the procedure of Church and Gilbert (1984) with the probes and temperatures mentioned in the legends to Figures 3-5 and 7. The subtelomeric probe used in Figure 3 was a $\sim 0.6-\mathrm{kb}$ EcoRI-XbaI fragment isolated from $K$. lactis telomere clone KL11B (McEachern and Blackburn 1994). The $\mathrm{XbaI}$ site lies within $0.1 \mathrm{~kb}$ from the start of telomeric DNA sequences in the KL11B clone. Oligonucleotide probes and hybridization wash conditions have been described previously (McEachern and Blackburn 1995).

Microscopy of microcolonies was performed with an Olympus BX40 microscope and microscopy of colonies was performed with an Olympus SZH10 microscope.

\section{Acknowledgments}

We thank Anat Krauskopf, Jagoree Roy, and John Prescott for comments on the manuscript. This work was supported by National Institutes of Health grant GM26259 to E.H.B. Laboratory facilities were provided in part by the Lucille P. Markey Charitable Trust.

The publication costs of this article were defrayed in part by payment of page charges. This article must therefore be hereby marked "advertisement" in accordance with 18 USC section 1734 solely to indicate this fact.

\section{References}

Allsopp, R.C., H. Vaziri, C. Patterson, S. Goldstein, E.V. Younglai, A.B. Futcher, C.W. Greider, and C.B. Harley. 1992. Telomere length predicts replicative capacity of human fibroblasts. Proc. Natl. Acad. Sci. 89: 10114-10118.

Becker, D.M. and L. Guarente. 1991. High-efficiency transformation of yeast by electroporation. Methods Enzymol. 194: 182-187.

Bennett, C.B., A.L. Lewis, K.K. Baldwin, and M.A. Resnick. 1993. Lethality induced by a single site-specific doublestrand break in a dispensable yeast plasmid. Proc. Natl. Acad. Sci. 90: 5613-5617.

Berman, J., C.Y. Tachibana, and B.-K. Tye. 1986. Identification of a telomere-binding activity from yeast. Proc. Natl. Acad. Sci. 83: 3713-3717.

Biessmann, H. and J.M. Mason. 1992. Genetics and molecular biology of telomeres. Adv. Genet. 30: 1081-1086.

Blackburn, E.H. 1994. Telomeres-No end in sight. Cell 77: 621-623.

Blasco, M.A., W. Funk, B. Villeponteau, and C.W. Greider. 1995. Functional characterization and developmental regulation of mouse telomerase RNA. Science 269: 1267-1270.

Boeke, J.D., F. LaCroute, and G.R. Fink. 1984. A positive selec- 
tion for mutants lacking orotidine-5' -phosphate decarboxylase activity in yeast: 5-Fluoroorotic acid resistance. Mol. Gen. Genet. 197: 345-346.

Bryan, T.M., A. Englezou, J. Gupta, S. Bacchetti, and R.R. Reddel. 1995. Telomere elongation in immortal human cells without detectable telomerase activity. EMBO /. 14: 42404248.

Church, G.M. and W. Gilbert. 1984. Genomic sequencing. Proc. Natl. Acad. Sci. 81: 1991-1995.

Cohn, M. and E.H. Blackburn. 1995. Telomerase in yeast. Science 269: 396-400.

Cooke, H. 1995. Non-programmed and engineered chromosome breakage. In Telomeres (ed. E.H. Blackburn and C.W. Greiderl, pp. 219-245. Cold Spring Harbor Laboratory Press, Cold Spring Harbor, NY.

Counter, C.M., A.A. Avilion, C.E. LeFeuvre, N.G. Stewart, C.W. Greider, C.B. Harley, and S. Bacchetti. 1992. Telomere shortening associated with chromosome instability is arrested in immortal cells which express telomerase activity. EMBO \%. 11: 1921-1929.

Counter, C.M., H.W. Hirte, S. Bacchetti, and C.B. Harley. 1994. Telomerase activity in human ovarian carcinoma. Proc. Natl. Acad. Sci. 91: 2900-2904.

Fang, G. and T.R. Cech. 1995. Telomere proteins. In Telomeres (ed. E.H. Blackburn and C.W. Greider), pp. 69-105. Cold Spring Harbor Laboratory Press, Cold Spring Harbor, NY.

Feng, J., W.D. Funk, S.-S. Wang, S.L. Weinrich, A.A. Avilion, C.-P. Chiu, R.R. Adams, E. Chang, R.C. Allsopp, J. Yu, S. Le, M.D. West, C.B. Harley, W.H. Andrews, C.W. Greider, and B. Villeponteau. 1995. The RNA component of human telomerase. Science 269: 1236-1240.

Garvik, B., M. Carson, and L. Hartwell. 1995. Single-stranded DNA arising at telomeres in $c d c 13$ mutants may constitute a specific signal for the RAD9 checkpoint. Mol. Cell. Biol. 15: 6128-6138.

Greider, C.W. 1995. Telomerase biochemistry and regulation. In Telomeres (ed. E.H. Blackburn and C.W. Greider), pp. 3568. Cold Spring Harbor Laboratory Press, Cold Spring Harbor, NY.

Greider, C.W. and E.H. Blackburn. 1989. A telomeric sequence in the RNA of Tetrahymena telomerase required for telomere repeat synthesis. Nature 337: 331-337.

Haber, J.E. 1995. In vivo biochemistry: Physical monitoring of recombination induced by site-specific endonucleases. BioEssays 17: 609-620.

Harley, C.B., A.B. Futcher, and C.W. Greider. 1990. Telomeres shorten during aging of human fibroblasts. Nature 345: 458460.

Hastie, N.D., M. Dempster, M.G. Dunlop, A.M. Thompson, D.K. Green, and R.C. Allshire. 1990. Telomere reduction in human colorectal carcinoma and with aging. Nature 346: 866-868.

Henderson, E. 1995. Telomere DNA structure. In Telomeres (ed. E.H. Blackburn and C.W. Greider), pp. 11-34. Cold Spring Harbor Laboratory Press, Cold Spring Harbor, NY.

Hollingsworth, N.M. and B. Byers. 1989. HOP1: A yeast meiotic pairing gene. Genetics 121: 445-462.

Kim, N.W., M.A. Piatyszek, K.R. Prowse, C.B. Harley, M.D. West, P.L.C. Ho, G.M. Coviello, W.E. Wright, S.L. Weinrich, and J.W. Shay. 1994. Specific association of human telomerase activity with immortal cells and cancer. Science 266: 2011-2015.

Klingerhutz, A.J., S. Barber, P.P. Smith, K. Dyer, and J.K. McDougall. 1994. Restoration of telomeres in human papillomavirus-immortalized human anogenital epithelial cells. Mol. Cell Biol. 14: 961-969.
Lindsey, J., N. McGill, L. Lindsey, D. Green, and H. Cooke. 1991. In vivo loss of telomeric repeats with age in humans. Mutat. Res. 256: 45-48.

Lingner, J., L.L. Hendrick, and T.R. Cech. 1994. Telomerase RNAs of different ciliates have a common secondary structure and a permuted template. Genes \& Dev. 8: 1984-1998.

Lundblad, V. and E.H. Blackburn. 1993. An alternative pathway for yeast telomere maintenance rescues est ${ }^{-}$senescence. Cell 73: 347-360.

Lundblad, V. and J.W. Szostak. 1989. A mutant with a defect in telomere elongation leads to senescence in yeast. Cell 57: 633-643.

McEachern, M.J. and E.H. Blackburn. 1994. A conserved sequence motif within the exceptionally diverse telomeric sequence of budding yeasts. Proc. Natl. Acad. Sci. 91: 34533457 .

- 1995. Runaway telomere elongation in telomerase RNA gene mutants of Kluyveromyces lactis. Nature 376: 403409.

McEachern, M.J. and J.B. Hicks. 1993. Unusually large telomeric repeats in the yeast Candida albicans. Mol. Cell Biol. 13: $551-560$.

Milne, G.T. and D.T. Weaver. 1993. Dominant negative alleles of $R A D 52$ reveal a DNA repair/recombination complex including Rad51 and Rad52. Genes \& Dev. 7: 1755-1765.

Morin, G.B. 1989. The human telomere terminal transferase enzyme is a ribonucleoprotein that synthesizes TTAGGG repeats. Cell 59: 521-529.

Murnane, J.P., L. Sabatier, B.A. Marder, and W.F. Morgan. 1994. Telomere dynamics in an immortal cell line. EMBO $/$. 13: 4953-4962.

Petes, T.D., R.E. Malone, and L.S. Syminton. 1991. Recombination in yeast. In The molecular and cellular biology of the yeast Saccharomyces cerevisiae (ed. J.R. Broach, J.R. Pringle, and E.W. Jones), pp. 407-521. Cold Spring Harbor Laboratory Press, Cold Spring Harbor, NY.

Pezzolo, A., G. Gimelli, A. Cohen, A. Lavaggetto, C. Romano, G. Fogu, and O. Zuffardi. 1993. Presence of telomeric and subtelomeric sequences at the fusion points of ring chromosomes indicates that the ring syndrome is caused by ring instability. Hum. Genet. 92: 23-27.

Prowse, K.R., A.A. Avilion, and C.W. Greider. 1993. Identification of a nonprocessive telomerase activity from mouse cells. Proc. Natl. Acad. Sci. 90: 1493-1497.

Rogan, E.M., T.M. Bryan, B. Hukku, K. Maclean, A.C.-M. Chang, E.L. Moy, A. Englezou, S.G. Warneford, L. DallaPozza, and R.R. Reddel. 1995. Alteration in p53 and p16 ${ }^{\mathrm{INK} 4}$ expression and telomere length during spontaneous immortalization of Li-Fraumeni syndrome fibroblasts. Mol. Cell. Biol. 15: 4745-4753.

Romero, D. and E.H. Blackburn. 1991. A conserved secondary structure for telomerase RNA. Cell 67: 343-353.

Saltman, D., R. Morgan, M.L. Cleary, and T. de Lange. 1993. Telomeric structure in cells with chromosome end associations. Chromosoma 102: 121-128.

Sandell, L.L. and V.A. Zakian. 1993. Loss of a yeast telomerearrest, recovery, and chromosome loss. Cell 75: 729-739.

Schiestl, R.H., P. Reynolds, S. Prakash, and L. Prakash. 1989. Cloning and sequence analysis of the Saccharomyces cerevisiae $R A D 9$ gene and further evidence that its product is required for cell cycle arrest induced by DNA damage. Mol. Cell. Biol. 9: 1882-1896.

Shay, J.W., W.E. Wright, D. Brasiskyte, and B.A. van der Hagen. 1993. E6 of human papilloma type 16 can overcome the M1 stage of immortalization in human mammary epithelial cells but not in human fibroblasts. Oncogene 8: 1407-1413. 
Shippen-Lentz, D. and E.H. Blackburn. 1990. Functional evidence for an RNA template in telomerase. Science 247: 546552.

Shore, D. 1995. Telomere position effects and transcriptional silencing in the yeast Saccharomyces cerevisiae. In Telomeres (ed. E.H. Blackburn and C.W. Greider), pp. 131-191. Cold Spring Harbor Laboratory Press, Cold Spring Harbor, NY.

Singer, M.S. and D.E. Gottschling. 1994. TLC1-Template RNA component of Saccharomyces cerevisiae telomerase. Science 266: 404-409.

Strahl, C. and E.H. Blackburn. 1996. Effects of reverse transcriptase inhibitors on telomere length and telomerase activity in two immortalized human cell lines. Mol. Cell. Biol. 16: 53-65.

Walmsley, R.W., C.S.M. Chan, B.K. Tye, and T.D. Petes. 1984. Unusual DNA sequences associated with the ends of yeast chromosomes. Nature 310: 157-160.

Wang, S.-S. and V.A. Zakian. 1990. Telomere-telomere recombination provides an express pathway for telomere acquisition. Nature 345: 456-458.

Weinert, T.A. and L.H. Hartwell. 1988. The RAD9 gene controls the cell cycle response to DNA damage in Saccharomyces cerevisiae. Science 241: 317-322.

Wray, L.V., M.M. Witte, R.C. Dickson, and M.I. Riley. 1987. Characterization of a positive regulatory gene, $L A C 9$, that controls induction of the lactose-galactose regulon of Kluyveromyces lactis: Structural and functional relationships to GAL4 of Saccharomyces cerevisiae. Mol. Cell Biol. 7: $1111-1121$.

Yu, G.-L. and E.H. Blackburn. 1991. Developmentally programmed healing of chromosomes by telomerase in Tetrahy mena. Cell 67: 823-832.

Yu, G.-L., J.D. Bradley, L.D. Attardi, and E.H. Blackburn. 1990. In vivo alteration of telomere sequences and senescence caused by mutated Tetrahymena telomerase RNAs. Nature 344: 126-132.

Zakian, V.A. 1995. Saccharomyces telomeres: Function, structure, and replication. In Telomeres (ed. E.H. Blackburn and C.W. Greider), pp. 107-137. Cold Spring Harbor Laboratory Press, Cold Spring Harbor, NY. 


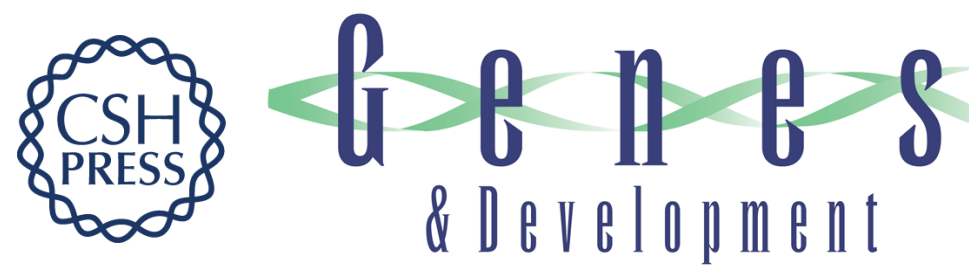

\section{Cap-prevented recombination between terminal telomeric repeat arrays (telomere CPR) maintains telomeres in Kluyveromyces lactis lacking telomerase.}

M J McEachern and E H Blackburn

Genes Dev. 1996, 10:

Access the most recent version at doi:10.1101/gad.10.14.1822

References This article cites 49 articles, 24 of which can be accessed free at:

http://genesdev.cshlp.org/content/10/14/1822.full.html\#ref-list-1

License

Email Alerting Service

Receive free email alerts when new articles cite this article - sign up in the box at the top right corner of the article or click here.

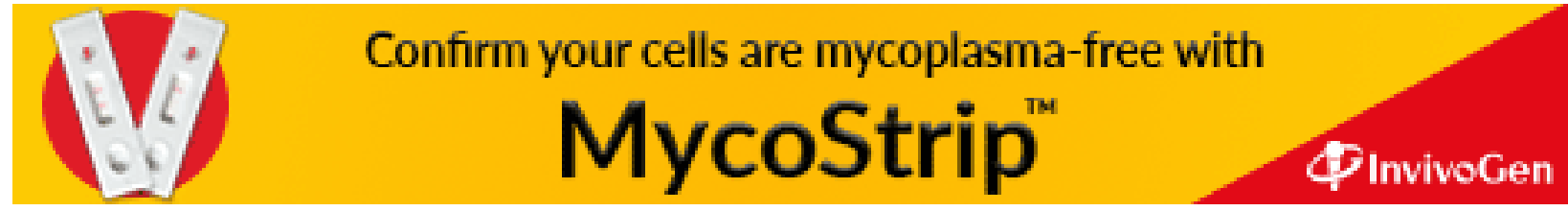

